\title{
Decreased biventricular myocardial deformation in fetuses with lower urinary tract obstruction
}

\author{
Ran Xu', Jiawei Zhou², Qichang Zhou² and Shi Zeng ${ }^{2 *}$
}

\begin{abstract}
Background: To observe myocardial deformations in fetuses with isolated lower urinary tract obstruction (LUTO) and identify the correlation between myocardial deformation and the severity of obstruction.

Methods: The strain (S), strain rate in systole (SRs) and strain rate in diastole (SRd) of the left and right ventricles at the first examination were prospectively analyzed and compared between fetuses with isolated LUTO and gestational age (GA)-matched normal control fetuses. Multiple regression analyses were used to assess the obstructive factors for impaired strain and strain rate, and the independent variables included bladder volume, sum of the bilateral pelvic diameters, sum of the bilateral ureteral diameters, mean bilateral renal artery pulsatility index, and amniotic fluid index.

Results: Thirty-six fetuses with isolated LUTO and 36 normal controls were enrolled. Overall, decreased S, SRs and SRd of both ventricles were noted in fetuses with LUTO $(p<0.001)$. Moreover, $S$ and SR were significantly negatively related to distended bladder volume $(p<0.001)$.

Conclusions: Fetuses with LUTO demonstrated decreased left and right myocardial deformation, and this impaired cardiac dysfunction was correlated with the urinary bladder volume. Evaluating the myocardial deformation in fetal LUTO could provide information to aid in parental counselling and intervention monitoring.
\end{abstract}

Keywords: lower urinary tract obstruction, myocardial deformation, strain, strain rate, fetus

\section{Background}

Lower urinary tract obstruction (LUTO), which occurs in between 2.2 and 3.3 per 10,000 births [1], refers to a heterogeneous group of urinary anatomic malformations with primary lesions on the bladder neck or urethra. Although the diagnostic accuracy is challenging, fetal LUTO can be detected by screening ultrasonography during the late first and second trimesters of pregnancy, characteristically presenting megacystis, various degrees of hydronephrosis and dilated ureters, macro- or

\footnotetext{
*Correspondence: shizeng@csu.edu.cn; doctorzshi@163.com

²Department of Ultrasound Diagnosis, The Second Xiangya Hospital, Central South University, 139 Renmin Road (M), Hunan 410011 Changsha, China

Full list of author information is available at the end of the article
}

microcysts in the kidney parenchyma and oligohydramnios $[2,3]$. Untreated fetal LUTO has up to a $45 \%$ perinatal mortality rate and approximately $30 \%$ morbidity in survivors $[4,5]$, principally due to lung hypoplasia and renal failure.

Cardiovascular dysfunction in the LUTO, triggered by an increased afterload accompanied by bladder compression and a compressed iliac artery, involves reduced pulmonary venous return due to lung dysplasia and the stimulation of neuro-hormonal mechanisms and may contribute to renal dysfunction and worse outcomes. However, few reports have focused on the cardiovascular effects in fetuses with LUTO. Cardiomegaly, pericardial effusion and ventricular hypertrophy are common in

(c) The Author(s). 2020 Open Access This article is licensed under a Creative Commons Attribution 4.0 International License, which permits use, sharing, adaptation, distribution and reproduction in any medium or format, as long as you give appropriate credit to the original author(s) and the source, provide a link to the Creative Commons licence, and indicate if changes were made. The images or other third party material in this article are included in the article's Creative Commons licence, unless indicated otherwise in a credit line to the material. If material is not included in the article's Creative Commons licence and your intended use is not permitted by statutory regulation or exceeds the permitted use, you will need to obtain permission directly from the copyright holder. To view a copy of this licence, visit http://creativecommons.org/licenses/by/4.0/ The Creative Commons Public Domain Dedication waiver (http://creativecommons.org/publicdomain/zero/1.0/) applies to the data made available in this article, unless otherwise stated in a credit line to the data. 
fetal LUTO [6-8]. Right ventricular filling compliance, such as a decreased tricuspid valve E/A ratio [6] and longer right ventricular isovolumetric relaxation time [8], as well as a worse left ventricular myocardial performance index [7], have been noted. To date, there are no detailed data on the characteristics of myocardial deformations in fetuses with isolated LUTO. Therefore, in this study, we aimed to (1) observe biventricular myocardial deformations in fetuses with isolated LUTO with giant bladder and (2) identify the correlation between myocardial deformation and the severity of LUTO.

\section{Methods}

A prospective cross-section observational study was conducted at the Second XiangYa Hospital of Central South University in China from January 2015 to December 2018. The study population consisted of pregnant women with an ultrasonic appearance of fetal LUTO, including a distended fetal urinary bladder (enlarged bladder failing to empty over a period of $45 \mathrm{~min}$ from the second trimester onward [9]), fetal hydronephrosis and ureterectasis (Fig. 1). We excluded suspected LUTO fetuses of less than 18 gestation weeks due to the hardacquiring heart image. The other exclusion criteria were as follows: presence of abnormalities in other organ systems; chromosomal abnormalities; and associated maternal complications, such as gestational diabetes, preeclampsia, and thyroid disease. Only the initial examination data were used to analyze if more than one scan was performed on the fetuses. None of the fetuses had any intervention done prior to initial evaluation (i.e. vesicocentesis). The perinatal outcome was noted. The etiology of the LUTO was determined based on the autopsy or postanatal examinations, such as physical check-up, urethroscope, voiding cystourethrography or surgical pathology. The normal control group was randomly collected from nonconsecutive, low-risk, gestational age (GA)-matched healthy pregnant women.
Written informed consent was obtained from all families, and this study was approved by the institutional review board at the Second Xiangya Hospital of Central South University.

Screening obstetrical ultrasound was performed for all fetuses by one investigator (Z.S.) using a Sequoia 512 ultrasound system with a $6 \mathrm{C} 2$ transducer at 2.56.0 MHz (Siemens Medical Solutions USA, Inc., Mountain View, CA, USA). The three diameters of the urinary bladder were measured and used to calculate the bladder volume using the following formula: longitudinal diameter $\times$ transverse diameter $x$ anteroposterior diameter $x$ $\pi / 6$ [10]. The pulsatility index (PI) of the renal arteries was measured in the renal arterial trunk away from the aorta and before any visible branches on a coronal view of the fetal abdomen, with an angle of insonation as close as possible to $0^{\circ}$. The presence of renal cortical cysts, the anteroposterior diameter of the pelvis, ureteral diameter, amniotic fluid index (AFI), PI of the middle cerebral artery (MCA) and umbilical artery (UI) were also recorded.

Fetal echocardiograms were performed at the same time after obstetrical ultrasound screening for all fetuses by one investigator (Z.QC) who was blinded to the group status. Standard and multiple views of the fetal heart were obtained [11], and specific attention was paid to the following issues for the purpose of this study: (1) cardiac/ thoracic ratio ( $\mathrm{C} / \mathrm{T}$ ratio), presence of pericardial effusion (defined as fluid $\geq 2 \mathrm{~mm}$ during diastole), thickness of the left and right ventricle; (2) presence of fusion of the $\mathrm{E}$ wave with the A wave across both mitral and tricuspid valves; and (3) presence of holosystolic mitral and tricuspid regurgitation. The myocardial deformation was performed by one observer who was blinded to the group status and echocardiography manifestation using vector velocity imaging software (VVI; Siemens Medical Solutions, Olympia, Washington). Briefly, as our previously
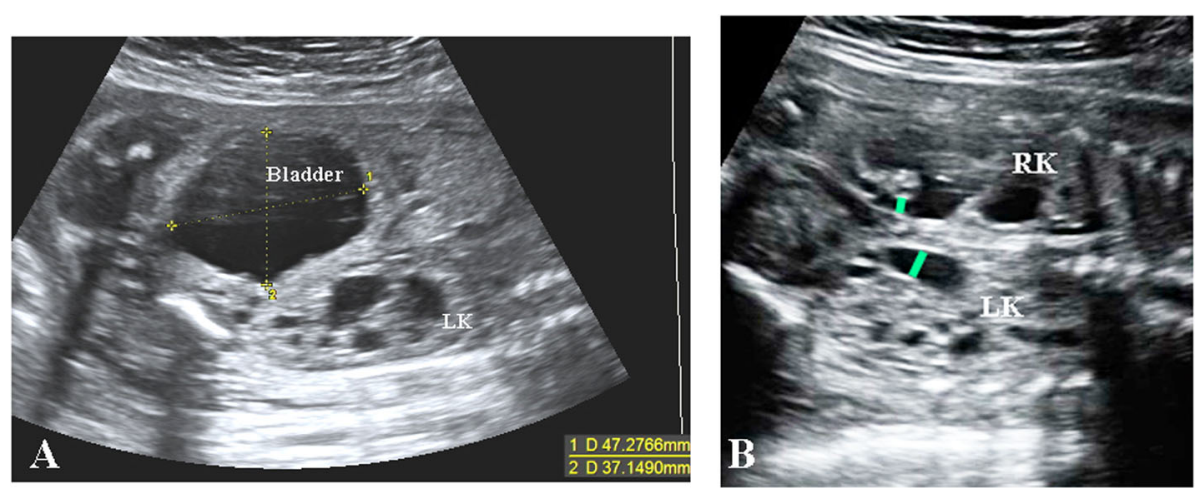

Fig. 1 Ultrasonic features of fetal LUTO showed a distended fetal urinary bladder (a), fetal hydronephrosis and ureterectasis (b, green lines identify bilateral dilated ureters). RK, right kidney; LK, left kidney 
reported [12, 13], a high-quality cine (40-50 frames/sec) of the apical four-chamber view was digitally stored, followed by identification of the cardiac cycle using $\mathrm{M}$ mode and tracing the ventricular endocardium. The myocardial deformation parameters, including the strain (S) and strain rate for systole (SRs) and the strain rate for diastole (SRd), were automatically calculated. S, SRs and SRd of both the left ventricle (LV) and right ventricle (RV) were recorded in this investigation.

Data are presented as the mean \pm SD or frequencies (percentage), as appropriate. Data were compared between normal controls and fetuses with LUTO using Student's t-tests or Fisher's exact test. After testing the correlations between myocardial deformation parameters and the severity of obstruction in the fetuses with LUTO using Pearson's correlation coefficient, multiple regression analyses with the stepwise method were calculated to identify the factors for impaired strain and strain rate; the independent variables included mean bilateral renal artery PI, bladder volume, sum of the bilateral pelvic diameters, sum of the bilateral ureteral diameters and AFI. Two-sided $\mathrm{P}<0.05$ was considered significant. All statistical analyses were performed using PASW statistics software [PASW (SPSS) statistics 18.0, IBM].

\section{Results}

A total of 59 fetuses with suspected LUTO were initially enrolled, but 23 cases were excluded, including 2 with excessive fetal movement resulting in poor echocardiographic images, 11 without follow-up, 6 with postnatally confirmed nonobstructive lesions (four infants with vesicoureteral reflux and two with normal micturition) and 4 with congenital syndrome (two infants with megacystis-microcolon-intestinal hypoperistalsis syndrome, one with macrosomia syndrome and one with prune belly syndrome). Finally, 36 fetuses with isolated LUTO and 36 GA-matched normal controls were studied. The GA at the initial examination was $21.5 \pm 1.2$ weeks. The perinatal outcomes of fetuses with LUTO are summarized in Table 1.

Compared with controls, the fetuses with LUTO undoubtedly had increased bladder volume, dilated pelvic and ureteral diameters and reduced amniotic fluid volume $(p<0.001)$. Eighteen $(50 \%)$ fetuses with LUTO showed classic keyhole signs. Although 8 fetuses with LUTO (22.2\%) demonstrated cortical renal cysts, the mean PI of the bilateral renal artery did not differ.

Regarding echocardiogram manifestations, fetuses with LUTO demonstrated an increased $\mathrm{C} / \mathrm{T}$ ratio $(p<0.001)$, more cases of RV hypertrophy and blood flow fusion across the tricuspid valve $(p<0.05)$. Moreover, the fetuses with LUTO demonstrated overall decreased myocardial deformation in both the left and right ventricles,
Table 1 The outcome of fetuses with LUTO $(n=36)$

\begin{tabular}{|c|c|}
\hline & Fetus with LUTO $(n=36)$ \\
\hline \multicolumn{2}{|l|}{ Postnatal diagnosis: } \\
\hline PUV, n (\%) & $20(55.5 \%)$ \\
\hline AUV, n (\%) & $5(13.9 \%)$ \\
\hline UA, n (\%) & $5(13.9 \%)$ \\
\hline US, n (\%) & $4(11.1 \%)$ \\
\hline MS, n (\%) & $2(5.5 \%)$ \\
\hline \multicolumn{2}{|l|}{ Outcome of pregnancy } \\
\hline TOP, n (\%) & $14(38.8 \%)$ \\
\hline IUFD, n (\%) & $3(8.3 \%)$ \\
\hline Live birth, n (\%) & $19(52.8 \%)$ \\
\hline \multicolumn{2}{|c|}{ Postnatal treatment and outcome } \\
\hline Follow-up period, month & $30.9 \pm 19.6$ \\
\hline Endoscopic surgery, n (\%) & 19 (100\%) \\
\hline a Renal dysfunction, n (\%) & $3(15.8 \%)$ \\
\hline
\end{tabular}

including the strain and strain rate in systole and diastole $(p<0.001$, Table 2$)$. Multiple regression analyses showed that the strain and strain rate of both ventricles were significantly negatively related to distended bladder volume $(p<0.001$, Fig. 2$)$.

\section{Discussion}

The effect on the myocardium in the LUTO group was present in utero, demonstrated as an overall decreased strain and strain rate in both the left and right ventricles, as well as negative correlations with the degree of obstruction.

Cardiac geometry in fetuses with LUTO showed an increased $\mathrm{C} / \mathrm{T}$ ratio and ventricular hypertrophy, similar to previous reports [6,7]. RV diastolic dysfunction in fetal LUTO was previously observed, reflected as a decreased tricuspid valve E/A ratio [6] and a longer RV isovolumetric relaxation time [8]. LV diastolic dysfunction was previously demonstrated as a shorter mitral valve (MV) inflow time and higher LV MPI [7]. Our study showed significantly decreased strain and strain rates in systole and diastole of both ventricles, indicating overall myocardial dysfunction in fetal LUTO.

Hemodynamic alterations in fetal LUTO contributes to cardiac dysfunction. On the one hand, both the afterload and preload of the RV were found to be increased in the setting of LUTO. The extended bladder could mechanically compress the iliac arteries and the origins of the umbilical arteries and cause an increased afterload 
Table 2 The ultrasonic manifestation and myocardial deformation in the cohort of studies $(n=72)$

\begin{tabular}{|c|c|c|c|}
\hline & Fetus with LUTO $(n=36)$ & Normal control $(n=36)$ & $P$ \\
\hline Maternal age, years & $30 \pm 6$ & $29 \pm 4$ & 0.36 \\
\hline GA at initial examination, weeks & $21.5 \pm 1.2$ & $21.5 \pm 1.2$ & 1 \\
\hline EFW at initial examination, $g$ & $404.5 \pm 89.3$ & $416.2 \pm 82.3$ & 0.92 \\
\hline Male, n (\%) & $34(94 \%)$ & $25(69.4 \%)$ & 0.01 \\
\hline \multicolumn{4}{|l|}{ Obstruction manifestation } \\
\hline Bladder volume, $\mathrm{cm}^{3}$ & $42.7 \pm 8.6$ & $8.6 \pm 3.8$ & $<0.001$ \\
\hline Keyhole sign, n (\%) & $18(50 \%)$ & 0 & $<0.001$ \\
\hline Pelvic diameters ${ }^{\mathrm{a}}, \mathrm{mm}$ & $18 \pm 4$ & $2 \pm 2$ & $<0.001$ \\
\hline Ureteral diameters $^{\mathrm{b}}, \mathrm{mm}$ & $4 \pm 1$ & 0 & $<0.001$ \\
\hline $\mathrm{RA}-\mathrm{PI} \mathrm{I}^{\mathrm{c}}$ & $2.00 \pm 0.10$ & $1.97 \pm 0.14$ & 0.28 \\
\hline Renal cortical cysts, n (\%) & $8(22.2 \%)$ & 0 & $<0.01$ \\
\hline Oligo-/anhydramnios, n (\%) & $22(61.1 \%)$ & 0 & $<0.001$ \\
\hline $\mathrm{AFI}$ & $42 \pm 36$ & $138 \pm 26$ & $<0.001$ \\
\hline \multicolumn{4}{|l|}{ Echocardiogram } \\
\hline $\mathrm{C} / \mathrm{T}$ & $0.35 \pm 0.06$ & $0.30 \pm 0.02$ & $<0.001$ \\
\hline$P E, n(\%)$ & $5(13.9 \%)$ & 0 & 0.05 \\
\hline LV hypertrophy, n (\%) & $4(11.1 \%)$ & 0 & 0.11 \\
\hline LV thickness, mm & $2.0 \pm 0.4$ & $1.9 \pm 0.3$ & 0.09 \\
\hline RV hypertrophy, n (\%) & $6(16.7 \%)$ & 0 & 0.03 \\
\hline RV thickness, mm & $2.1 \pm 0.4$ & $1.9 \pm 0.2$ & 0.05 \\
\hline MVR, n (\%) & $3(8.3 \%)$ & 0 & 0.24 \\
\hline TVR, n (\%) & $5(13.9 \%)$ & 0 & 0.05 \\
\hline MV fusion, n (\%) & $4(11.1 \%)$ & 0 & 0.11 \\
\hline TV fusion, n (\%) & 7 (19.4\%) & 0 & 0.01 \\
\hline \multicolumn{4}{|l|}{ Myocardial deformation } \\
\hline LV-S, \% & $-16.03 \pm 2.89$ & $-20.21 \pm 1.61$ & $<0.001$ \\
\hline LV-SRs, $\mathrm{s}^{-1}$ & $-1.57 \pm 0.27$ & $-2.07 \pm 0.17$ & $<0.001$ \\
\hline LV-SRd, $s^{-1}$ & $1.51 \pm 0.32$ & $1.95 \pm 0.43$ & $<0.001$ \\
\hline RV-S, \% & $-16.35 \pm 2.70$ & $-26.42 \pm 1.96$ & $<0.001$ \\
\hline RV-SRs, $s^{-1}$ & $-1.73 \pm 0.27$ & $-2.61 \pm 0.81$ & $<0.001$ \\
\hline RV-SRd, $s^{-1}$ & $1.81 \pm 0.26$ & $2.54 \pm 0.56$ & $<0.001$ \\
\hline
\end{tabular}

${ }^{\mathrm{a}}$ The sum of the anteroposterior diameter of the bilateral pelvis; ${ }^{\mathrm{b}}$ sum of the bilateral ureteral diameters; ${ }^{\mathrm{c}}$ The mean of the bilateral renal artery pulsatility index; GA gestational age; $E F W$ estimated fetal weight; $R A$ renal artery; $A F I$ amniotic fluid index; $C / T$ cardiothoracic ratio; $P E$ pericardial effusion; $L V$ left ventricle; $R V$ right ventricle; MVR mitral valve regurgitation; TVR tricuspid valve regurgitation; $S$ strain; $S R$ s strain rate in systole; $S R d$ strain rate in diastole

of the RV. Such vascular compression and increased impedance in the fetus with LUTO have been observed by Rychik J [6], showing a lower PI in the lower distal descending aorta and bilateral iliac arteries. Increased preload is caused by renin-angiotensin-aldosterone system (RAAS)-mediated fluid overload. Experiments on fetal sheep [14] demonstrated that fetal partial ureteral obstruction can cause upregulation of the levels of renin, angiotensinogen and angiotensin receptors, which result in water and salt retention. On the other hand, the preload of the LV was decreased due to reduced pulmonary vein return associated with lung hypolasia, which is common in fetal LUTO. Such a diminished preload of the LV in fetal LUTO has been observed by Cohen J [7], showing a reduced LV cardiac index, and could result in diminished forward flow to the coronary arteries and less myocardial perfusion.

Other contributions to the overall cardiac dysfunction are triggered by obstructive uropathy. Renal damage and loss of renal function have been observed in fetuses with LUTO through fetal histopathology and urinary/serum tests. Fetal and neonatal animal models of ureteral obstruction have demonstrated decreased renal mass, reduced number of nephrons, loss of tubular cells and 


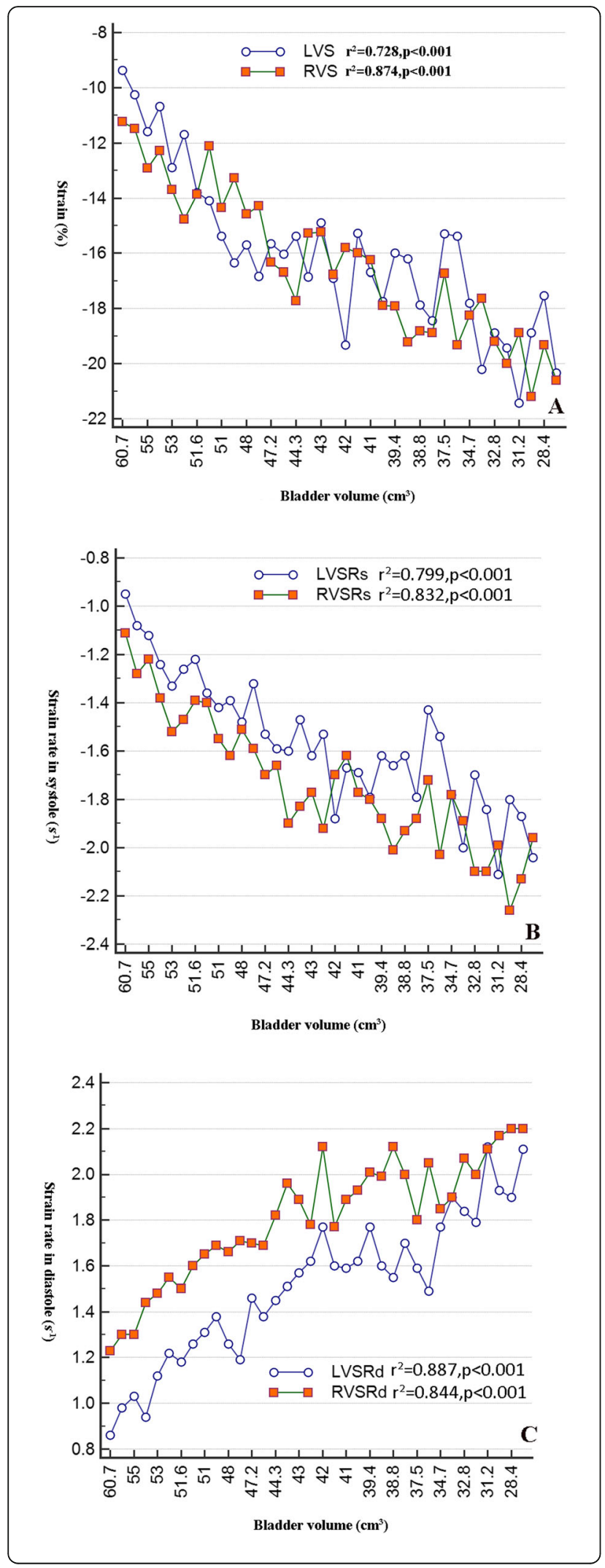

Fig. 2 The scatter plot shows that a distended bladder volume was significantly related to decreased strain $(\mathbf{a})$, strain rate in systole $(\mathbf{b})$ and strain rate in diastole (c) of both ventricles in fetuses with LUTO. $\mathrm{S}$, strain; SRs, strain rate in systole; SRd, strain rate in diastole; LV, left ventricle; RV, right ventricle

collecting ducts, a decreased glomerular number and glomerular filtration rate, and increased interstitial fibrosis $[15,16]$. Furthermore, human fetal autopsy has revealed higher rates of mesenchymal and tubular apoptosis [17]. Abnormal fetal urinary/serum examinations in LUTO, reflected as increased urinary $\beta-2$ microglobulin [18], urinary sodium and calcium [18], and 12 fetal urinary peptides [19], as well as serum $\beta$-2-microglobulin [20], have been observed and noted to have strong predictive value for poor postnatal renal function. The renal dysfunction in fetal LUTO, through a number of pathways [21] relevant to hormonal responses, inflammation/oxidative stress and metabolic changes, can induce cardiac fibroblast proliferation[22], endothelial dysfunction [23] and cardiac remodeling $[24,25]$ and eventually cause overall cardiac dysfunction.

Our study found that fetuses with severe bladder extension were associated with worse myocardial strain and strain rates. On the one hand, the larger the urinary bladder was, the higher the compression on the iliac artery and the intraabdominal pressure were. As a result, the hemodynamic contributor to cardiac malfunction was magnified. On the other hand, the larger the urine bladder was, the worse was the renal dysfunction presented. Recently, Fontanella F [26] found that the bladder volume at diagnosis was the best single predictor of a severely decreased estimated glomerular filtration rate in LUTO fetuses referred before the 26th week of gestation. Moreover, an increased bladder volume was also correlated with oligohydramnios in our cohort, and oligohydramnios was reported to predict postnatal renal impairment with a positive likelihood ratio of 17.0 [27] Such impairment of renal function can result in cardiac dysfunction via the abovementioned pathways.

The potential limitation of this study was the absence of invasive fetal urine/serum biometry due to the lack of fetal intervention in our region. However, we measured a correlation between ultrasound features and cardiac deformation, which could provide more useful information for prenatal counseling for most developing countries and regions. In addition, it is necessary to further examine the characteristics of myocardial deformation in LUTO along the duration of pregnancy as well as postinterventionally. 


\section{Conclusions}

In summary, the strain and strain rate of both ventricles were decreased in fetuses with isolated LUTO, and such cardiac dysfunction was correlated with the urinary bladder volume. Evaluating the myocardial deformation in fetal LUTO could provide information to help in parental counselling and intervention monitoring.

\section{Abbreviations}

LUTO: Lower urinary tract obstruction; S: Strain; SRs: Strain rate for systole; SRd: Strain rate for diastole

\section{Acknowledgements}

Not applicable.

\section{Authors' contributions}

"X.R performed collection and analyses data and drafted the paper. Z.J and Z.QC performed the fetal ultrasound. Z.S desinged this work and reivesed the paper. All authors read and approved the final manuscript.

\section{Funding}

This study was supported by the State Natural Sciences Foundation of China (nos. 81871372,81501497). The funding source had no involvement in study design, collection and interpretation of data, writing of paper, and decision to submit paper for publication.

\section{Availability of data and materials}

The datasets used and/or analysed during the current study are available from the corresponding author on reasonable request.

\section{Ethics approval and consent to participate}

Written informed consent was obtained from the parents, and this study was approved by the institutional review board at the Second Xiangya Hospital of Central South University.

\section{Consent for publication}

Written informed consent was obtained from the parents.

\section{Competing interests}

The authors declare that they have no competing interests.

\section{Author details}

${ }^{1}$ Department of Urology, The Second Xiangya Hospital, Central South University, 410011 Changsha, Hunan, China. ²Department of Ultrasound Diagnosis, The Second Xiangya Hospital, Central South University, 139 Renmin Road (M), Hunan 410011 Changsha, China.

Received: 19 December 2019 Accepted: 3 August 2020

Published online: 12 August 2020

\section{References}

1. Malin G, Tonks AM, Morris RK, Gardosi J, Kilby MD. Congenital lower urinary tract obstruction: a population-based epidemiological study. BJOG. 2012 119:1455e64.

2. Robyr R, Benachi A, Daikha-Dahmane F, Martinovich J, Dumez Y, Ville $Y$. Correlation between ultrasound and anatomical findings in fetuses with lower urinary tract obstruction in the first half of pregnancy. Ultrasound Obstet Gynecol. 2005;25:478e82.

3. Fontanella F, Duin LK, Adama van Scheltema PN, Cohen-Overbeek TE, Pajkrt E, Bekker M, Willekes C, Bax CJ, Gracchi V, Oepkes D, Bilardo CM. Prenatal diagnosis of LUTO: improving diagnostic accuracy. Ultrasound Obstet Gynecol. 2018:52:739-43.

4. Freedman AL, Johnson MP, Gonzalez R. Fetal therapy for obstructive uropathy: past, present.future? Pediatr Nephrol. 2000;14:167e76.

5. Cheung KW, Morris RK. Kilby MD.Congenital urinary tract obstruction.Best Pract Res Clin Obstet Gynaecol 2019. doi: https://doi.org/10.1016/j.bpobgyn. 2019.01.003.
6. Rychik J, McCann M, Tian Z, Bebbington M, Johnson MP. Fetal cardiovascular effects of lower urinary tract obstruction with giant bladder. Ultrasound Obstet Gynecol. 2010;36:682-6.

7. Cohen J, Levasseur S, Simpson L, Miller R, Freud L. Cardiac findings and hemodynamic changes associated with severe lower urinary tract obstruction in utero. Ultrasound Obstet Gynecol. 2019. doi:https://doi.org/ 10.1002/uog.20271.

8. Graupner O, Enzensberger C, Götte M, Wolter A, Mueller V, Kawecki A, Weber S, Degenhardt J, Herrmann J, Axt-Fliedner R. Myocardial function in fetuses with lower urinary tract obstruction: Is there a cardiac remodeling effect due to renal damage? Prenat Diagn 2019. doi: https://doi.org/10. 1002/pd.5453. [Epub ahead of print].

9. Taghavi K, Sharpe C, Stringer MD. Fetal megacystis: a systematic review. J Pediatr Urol. 2017;13:7e15.

10. Campbell S, Wladimiroff JW, Dewhurst CJ. The antenatal measurement of fetal urine production. J Obstet Gynaecol Br Commonw. 1973;80: 680-6.

11. Rychik J, Ayres N, Cuneo B, Gotteiner N, Hornberger L, Spevak PJ, Van Der Veld M. American Society of Echocardiography guidelines and standards for performance of the fetal echocardiogram. J Am Soc Echocardiogr. 2004;17: 803-10.

12. Zeng S, Zhou J, Peng Q, Deng W, Zang M, Wang T, Zhou Q. Sustained Chronic Maternal Hyperoxygenation Increases Myocardial Deformation in Fetuses with a Small Aortic Isthmus at Risk for Coarctation. J Am Soc Echocardiogr. 2017;30:992-1000.

13. Peng QH, Zhou QC, Zeng S, Tian LQ, Zhang M, Tan Y, Pu DR. Evaluation of regional left ventricular longitudinal function in 151 normal fetuses using velocity vector imaging. Prenat Diagn. 2009;29:1149-55.

14. Ayan S, Roth JA, Freeman MR, Bride SH, Peters CA. Partial ureteral obstruction dysregulates the renal renin-angiotensin system in the fetal sheep kidney. Urology. 2001;58:301-6.

15. Chevalier RL, Thornhill BA, Chang AY, Cachat F, Lackey A. Recovery from release of ureteral obstruction in the rat: relationship to nephrogenesis. Kidney Int. 2002:61:2033-43.

16. Cachat F, Lange-Sperandio B, Chang AY, Kiley SC, Thornhill BA, Forbes MS, Chevalier RL. Ureteral obstruction in neonatal mice elicits segmentspecific tubular cell responses leading to nephron loss. Kidney Int. 2003; 63:564-75.

17. Poucell-Hatton S, Huang M, Bannykh S, Benirschke K, Masliah E. Fetal obstructive uropathy: patterns of renal pathology. Pediatr Dev Pathol. 2000; 3:223-31.

18. Abdennadher W, Chalouhi G, Dreux S, Rosenblatt J, Favre R, Guimiot F, Salomon LJ, Oury JF, Ville Y. Muller.Fetal urine biochemistry at 13-23 weeks of gestation in lower urinary tract obstruction: criteriafor in-utero treatment. Ultrasound Obstet Gynecol. 2015;46:306-11.

19. Klein J, Lacroix C, Caubet C, Siwy J, Z“ urbig P, Dakna M, Muller F, Breuil B, Stalmach A, Mullen W, Mischak H, Bandin F, Monsarrat B, Bascands JL, Decramer S, Schanstra JP. Fetal urine peptides to predict postnatal outcome of renal disease in fetuses with posterior urethral valves (PUV). Sci Transl. 2013;5:198ra106

20. Berry SM, Lecolier B, Smith RS, Bercau G, Dombrowski MP, Puder KS, Kithier $K$, Bidat $L$, Johnson MP, Cotton DB. Predictive value of fetal serum $\beta 2$ microglobulin for neonatal renal function. Lancet. 1995:345:1277-8.

21. Schefold JC, Filippatos G, Hasenfuss G, Anker SD, von Haehling S. Heart failure and kidney dysfunction: epidemiology, mechanisms and management. Nat Rev Nephrol. 2016;12:610-23.

22. Sharma UC, Pokharel S, van Brakel TJ, van Berlo JH, Cleutjens JP, Schroen B, André S, Crijns HJ, Gabius HJ, Maessen J, Pinto YM. Galectin-3 marks activated macrophages in failure-prone hypertrophied hearts and contributes to cardiac dysfunction. Circulation. 2004;110:3121-8.

23. Vaziri ND, Dicus M, Ho ND, Boroujerdi-Rad L, Sindhu RK. Oxidative stress and dysregulation of superoxide dismutase and NADPH oxidase in renal insufficiency. Kidney Int. 2003;63:179-85.

24. Levin A, Thompson CR, Ethier J, Carlisle EJ, Tobe S, Mendelssohn D, Burgess $E$, Jindal K, Barrett B, Singer J, Djurdjev O. Left ventricular mass index increase in early renal disease: impact of decline in hemoglobin. Am Kidney Dis. 1999;34:125-34.

25. Achinger SG, Ayus JC. Left ventricular hypertrophy: is hyperphosphatemia among dialysis patients a risk factor?J. Am Soc Nephrol. 2006;17:255-61.

26. Fontanella F, van Scheltema PNA, Duin L, Cohen-Overbeek TE, Pajkrt E, Bekker MN, Willekes C, Oepkes D, Bilardo CM. Antenatal staging of 
congenital lower urinary tract obstruction. Ultrasound Obstet Gynecol. 2019; 53:520-4.

27. Harper L, Waubant A, Vignes J, Amat S, Dobremez E, Lefevre Y, Ferdynus C. Can quantity of amniotic fluid reliably predict postnatal renal function in boys with posterior urethral valves: a decision curve analysis. Prenat Diagn. 2017;37:931-4

\section{Publisher's Note}

Springer Nature remains neutral with regard to jurisdictional claims in published maps and institutional affiliations.

Ready to submit your research? Choose BMC and benefit from:

- fast, convenient online submission

- thorough peer review by experienced researchers in your field

- rapid publication on acceptance

- support for research data, including large and complex data types

- gold Open Access which fosters wider collaboration and increased citations

- maximum visibility for your research: over $100 \mathrm{M}$ website views per year

At $B M C$, research is always in progress.

Learn more biomedcentral.com/submissions 